\title{
Human mesenchymal stem cells from bone marrow express tumor endothelial and stromal markers
}

\author{
REBECCA G. BAGLEY ${ }^{1}$, WILLIAM WEBER ${ }^{1}$, CECILE ROULEAU $^{1}$, MIN YAO $^{1}$, NAKAYUKI HONMA ${ }^{2}$, \\ SHIRO KATAOKA ${ }^{2}$, ISAO ISHIDA ${ }^{2}$, BRUCE L. ROBERTS ${ }^{1}$ and BEVERLY A. TEICHER ${ }^{1}$ \\ ${ }^{1}$ Genzyme Corporation, 49 New York Ave., Framingham, MA 01701-9322, USA \\ ${ }^{2}$ Kirin Pharma Co., Ltd., 3 Miyahara, Takasaki, Japan
}

Received November 14, 2008; Accepted December 19, 2008

DOI: 10.3892/ijo_00000187

\begin{abstract}
Tumor development is a complex and dynamic process that involves malignant, vascular, and stromal cells. Endosialin is a tumor endothelial marker (TEM) present in the microvasculature and stroma of human tumors. Cancerassociated fibroblasts (CAF) have been implicated in promoting tumor development and have been associated with mesenchymal stem cells (MSC). Since stem/progenitor cells recruited either from bone marrow or residing in nearby tissues can contribute to pathological processes we investigated endosialin in MSC using a novel monoclonal antibody. Endosialin is highly expressed by $\mathrm{CAF}$ and human bone marrow-derived MSC. MSC can form networks in a tube formation assay that is inhibited by an anti-endosialin antibody. Immunohistochemistry for human endosialin in xenograft tumors following co-injection of MSC and cancer cells identified MSC in tumor stroma. MSC are a potential target for anticancer therapeutic intervention and endosialin expression offers a new tool for the identification of MSC. Endosialin expression by both CAF and MSC further implies the potential contribution of MSC to tumor stroma via differentiation into tumor stromal fibroblasts.
\end{abstract}

Correspondence to: Rebecca G. Bagley, Genzyme Corporation, 49 New York Ave., Framingham, MA 01701-9322, USA

E-mail: rebecca.bagley@genzyme.com

Abbreviations: MSC, mesenchymal stem cells; CAF, cancerassociated fibroblasts; TEM, tumor endothelial marker; EC, endothelial cells; SAGE, serial analysis of gene expression; $\alpha \mathrm{SMA}$, alpha smooth muscle actin; PCNA, proliferating cell nuclear antigen; RT-PCR, reverse transcription polymerase chain reaction; FBS, fetal bovine serum; RBC, red blood cell; PBS, phosphatebuffered saline; BSA, bovine serum albumin; ANTXR1, anthrax toxin receptor 1; FSP, fibroblast surface protein; TAF, tumorassociated fibroblasts; bFGF, basic fibroblast growth factor; EGF, epidermal growth factor; IGF-1, insulin growth factor 1

Key words: mesenchymal, stem, tumor, vasculature, stroma, endosialin, tumor endothelial marker

\section{Introduction}

The understanding of cancer has moved beyond malignant cells to a systemic disease directed by the malignant cells but critically involving a variety of 'normal' cells including stromal cells, endothelial cells, and infiltrating cells (1). This multicellular nature of solid tumors including stem/progenitor cells has invited comparisons of the development of tumors to organ-like entities (2). Cancer-associated fibroblasts (CAF) and tumor-associated fibroblasts (TAF) are associated with driving the progression of several cancer types including melanoma, breast, colon, and prostate (3-8). CAF can induce the epithelial to mesenchymal transition of malignant cells and promote angiogenesis through the SDF-1/CXCR4 pathway by secreting SDF-1 $(9,10)$.

Molecular profiling technologies such as serial analysis of gene expression (SAGE) have allowed identification of potential molecular targets in specific cellular tumor components. For example, a series of tumor endothelial markers (TEM) were found to be upregulated in the vasculature of a human colon carcinoma compared to normal colon tissue (11). Endosialin (CD248) was called TEM 1 and has also been detected in the blood vessels of highly invasive brain tumors and bladder cancers associated with the more aggressive forms of breast cancer and malignant, perivascular and stromal cells in sarcomas (12-16). Endosialin is a type I cell surface glycoprotein of 757 amino acids with a predicted molecular mass of $80.9 \mathrm{kDa}(17,18)$. One binding partner of endosialin was identified as the metastasis-related protein Mac-2 BP/90K (19). The extracellular matrix protein fibronectin has recently been demonstrated to be another binding partner of endosialin (20).

Although identified as a TEM, endosialin is expressed by CAF/TAF in several tumor types and by malignant cells in some sarcomas, melanoma metastasis, and squamous cell carcinomas $(14,16,21)$. During lymphoid tissue development endosialin is expressed on a subset of stromal cells and in fibroblasts of the mesenchyme of developing mouse embryos $(22,23)$. Since CAF can influence breast tumor development, we have investigated the expression of endosialin and other TEM in CAF derived from human breast carcinomas.

Recently MSC have been implicated in promoting breast cancer metastasis (24). Additionally, MSC can differentiate into CAF-like cells with the phenotypic properties of myo- 
fibroblasts (25). Since stem cells can contribute to pathological processes we have investigated endosialin in MSC using a novel anti-endosialin monoclonal antibody. MSC express high levels of endosialin indicating that this molecular marker may be important in these undifferentiated precursor cells. In a novel assay, MSC tube formation in vitro was inhibited by anti-endosialin. Stromal MSC could be detected by immunohistochemical methods in tumors resulting from a subcutaneous co-injection of human MSC along with human DLD-1 colon carcinoma cells into immunodeficient mice. MSC also express other TEM. These findings implicate the potential involvement of MSC in tumor growth by differentiating into CAF. Furthermore, targeting endosialin may offer therapeutic benefit by inhibiting malignant processes that promote cancer.

\section{Materials and methods}

Materials. Human MSC isolated from healthy subject bone marrow aspirates were purchased from Lonza and grown in MSC basal media supplemented with 10\% FBS, L-glutamine, and penicillin/streptomycin (Lonza, Walkersville, MD). MSC are $\mathrm{CD} 105^{+} / \mathrm{CD} 166^{+} / \mathrm{CD} 29^{+} / \mathrm{CD} 44^{+} / \mathrm{CD} 14^{-} / \mathrm{CD} 34 / \mathrm{CD} 45^{-}$. MSC are characterized by their capacity for self-renewal and ability to differentiate into osteocytes, chondrocytes, and adipocytes (26). For adipocyte differentiation, MSC were exposed alternatively to adipocyte induction and maintenance medium (Lonza) every three days for several weeks. Adipocytes were fixed with formalin and stained with oil red $\mathrm{O}$ stain. MSC were between passages 4-8 for experiments.

DLD-1 human colon carcinoma cells (ATCC, Manassas, VA) were grown in RPMI-1640 with $10 \%$ FBS and penicillin/ streptomycin (Invitrogen Corp., Carlsbad, CA). The DLD-1 cell line was developed from the primary surgical sample of a male patient with Dukes' type C colorectal adenocarcinoma (27).

The anti-human endosialin antibody is a fully human monoclonal antibody isolated after inoculation of the $\mathrm{KM}^{\mathrm{TM}}$ mouse with mouse L929 cells transfected to express very high levels of human endosialin $(28,29)$. The control antibody is a fully human antibody raised against dinitrophenol (DNP) in the KM mouse. The highest producing hybridoma cells were seeded in protein-free hybridoma medium (PFHM-II) with 5\% low IgG FBS (Invitrogen) and expanded in serum-free PFHM-II. The antibody from conditioned media was captured on a Protein A sepharose column (GE Healthcare, Piscataway, $\mathrm{NJ}$ ) equilibrated with $50 \mathrm{mM}$ sodium phosphate, $25 \mathrm{mM}$ $\mathrm{NaCl}, \mathrm{pH}$ 7.1. The conditioned media loaded on the column was washed first with $50 \mathrm{mM}$ sodium phosphate, $25 \mathrm{mM}$ $\mathrm{NaCl}, \mathrm{pH} 7.1$, then $10 \mathrm{mM}$ sodium succinate, $\mathrm{pH}$ 6.0. The column was eluted with $10 \mathrm{mM}$ sodium succinate, $\mathrm{pH} 3.75$. The eluates with antibody were sterile filtered through a $0.22 \mu \mathrm{m}$ PES membrane (Whatman, Inc., Florham Park, NJ). The antibody was formulated in PBS.

Isolation of primary breast cancer CAF. Through an IRBapproved protocol and patients' informed consent, surgically excised breast tumor specimens were received on wet ice in RPMI-1640 medium/10\% FBS/penicillin/streptomycin (Invitrogen) and processed within $24 \mathrm{~h}$ of the surgery. The tumors were minced and dissociated in DMEM high glucose media/1\% FBS (Invitrogen)/20 mM HEPES (Invitrogen)/ $0.4 \mathrm{mg} / \mathrm{ml}$ elastase (Roche Applied Science, Minneapolis, $\mathrm{MN}) / 4 \mathrm{mg} / \mathrm{ml}$ collagenase (Roche Applied Science), and penicillin/streptomycin (Invitrogen). Tumor minceates were digested for $60-90 \mathrm{~min}$ at $37^{\circ} \mathrm{C}$ in a rotational incubator. The resulting cell suspensions were sequentially filtered through nylon membranes (Tetko, Inc., Briarcliff Manor, NY) with mesh sizes of $40-500 \mu \mathrm{m}$. The single cell suspensions were centrifuged at $1200 \mathrm{rpm}$ for $10 \mathrm{~min}$ at $4^{\circ} \mathrm{C}$. The resulting pellets were suspended in $30 \mathrm{ml}$ of cold PBS (Invitrogen) $/ 0.5 \%$ BSA. All remaining procedures except red blood cell (RBC) lysis, were carried out at $4^{\circ} \mathrm{C}$ using $\mathrm{PBS} / 0.5 \% \mathrm{BSA}$ buffer kept cold on ice. The cells were washed twice in PBS/0.5\% BSA. The combined pellets were suspended in $6 \mathrm{ml}$ of RBC lysis buffer (Biosource International, Camarillo, CA) and incubated at room temperature for $10 \mathrm{~min}$ with occasional agitation. The cells were washed by centrifugation and suspended in $30 \mathrm{ml}$ cold $\mathrm{PBS} / 0.5 \% \mathrm{BSA}$. Finally, the combined cell pellets were suspended in $1 \mathrm{ml}$ of cold PBS/ $0.5 \%$ BSA.

The cell isolation procedures were carried out in a cold room. Magnetic beads were washed and unconjugated antibodies anti-CD64 (BD Pharmingen, San Diego, CA) and anti-NG2 (Chemicon, Temecula, CA) were coupled to beads (Dynal Biotech) according to the manufacturer's instructions. White blood cells were depleted by magnetic beads coupled with antibodies directed toward CD14, CD45, and CD64 (Dynal Biotech, Brown Deer, WI). A 1:1:1 mixture of each bead in $0.22 \mathrm{ml}$ was added to the single cell suspensions in buffer $(1 \mathrm{ml})$ and rotated end-over-end at $4^{\circ} \mathrm{C}$ for $30 \mathrm{~min}$ at slow speed. Beads with attached cells were removed by a magnet and the remaining cell suspension was washed according to the manufacturer's instructions. Cells were pelleted by centrifugation for $8 \mathrm{~min}$ at $1200 \mathrm{rpm}$. The suspended cells were sequentially exposed to beads conjugated with antibodies to the epithelial marker (BerPE4) (Dynal Biotech), NG2, or to CD31 (Dynal Biotech) for epithelial, pericyte, and endothelial cell removal. The remaining cells (CAF) were cultured in basal media with $2 \%$ FBS and $2 \mathrm{ng} / \mathrm{ml}$ each of bFGF, EGF, and IFG-1 (Sciencell Research Labs). CAF were between passages 2-4 for experiments.

$R T-P C R$. RNA was isolated from MSC by exposure to TRIzol (Invitrogen) and chloroform extraction. Samples were applied to RNeasy miniprep spin columns (Qiagen, Valencia, CA) and purified according to the manufacturer's instructions. cDNA was generated using the High Capacity cDNA Archive Kit (Applied Biosystems, Foster City, CA). Equal loading of the samples was verified by measurement of $18 \mathrm{~s}$ levels. For expression of TEM, real-time PCR analysis was performed using the fluorogenic 5'-nuclease assay TEM primers and probe sequences are as follows: TEM 1, forward primer: GCAAGTGGCGAGCACCGCTGGCT; reverse primer: GGCAGGCGCCCTCGAAGCCA; probe: CGCTGGCTGTC GACGGCTACCTGTGCCAGTT. TEM 3, forward primer: TACCAACATTTCGGCTGTGG; reverse primer: GATACA CAGGGGCCACATCT; probe: TGACCCCATTACCCACA TGCCTCCAGTTT. TEM 5, forward primer: AAGGCCTGC 
AGCCGCATCGT; reverse primer: GCAGGTCAGGCCCA CGTAGCTG; probe: CACGTTCCTCGCATTCACTGAGA TGTGCTGG. TEM 7, forward primer: CACCATGACGGC CGCATTGT; reverse primer: AGGCCGGTTTTGACAGGA TGC; probe: CTTTGCCTATAAAGAGATCCCTATGTCT GTCCCGG. TEM 8, forward primer: CCGGAGCAGGAAT ATGAATT; reverse primer: GACCCACAAGGCATCGA; probe: TCCCCCCGGAAGTGGTACTC. TEM 9, forward primer: GCAAGGACAAGAAGTGCGTGT; reverse primer: GATGTAGGGCAAGGCTGTCA; probe: CAGTCCTCTCG GCTGGCTGTC.

Flow cytometry. Breast cancer CAF or MSC were collected by brief exposure to $0.25 \%$ Trypsin/ $1 \mathrm{mM}$ EDTA (Invitrogen) and washed twice in cold PBS containing $5 \mathrm{mM}$ EDTA and $5 \%$ FBS. Approximately $1-2 \times 10^{5}$ cells were suspended in final volume of $100 \mu \mathrm{l}$ of buffer and incubated with the primary antibody for $1 \mathrm{~h}$ on ice. The cells were washed twice with buffer and incubated with a secondary antibody for $45 \mathrm{~min}$ on ice. The cells were again washed twice with buffer and suspended in a final volume of $500 \mu 1$ for analysis. Primary antibodies were used at a concentration of $10 \mu \mathrm{g} / \mathrm{ml}$. The secondary antibodies either PE-labeled goat anti-rabbit IgG or PE-labeled goat anti-mouse IgG were used at a 1:50 dilution (Jackson Immunoresearch Labs, West Grove, PA). Primary antibodies used were anti-endosialin, and rabbit polyclonal anti-TEM 2, 4, 5, 7, and 8 (Genesis Biotech Inc., Taiwan, R.O.C.).

Tube formation. Matrigel (BD Biosciences, Bedford, MA) was added to a 48 -well plate $(150 \mu \mathrm{l}$ per well). MSC were suspended by brief exposure to $0.25 \%$ Trypsin (Invitrogen) and for pre-incubations were exposed to anti-endosialin or negative control antibody for $45 \mathrm{~min}$. MSC were plated onto reduced growth factor Matrigel in $300 \mu 1$ in PBS/basal media/FBS (49:49:2) in triplicate. Without preincubation the antibodies were added at the time the cells were placed into the wells. The cells were incubated at $37^{\circ} \mathrm{C}$ with humidified $95 \%$ air $/ 5 \% \mathrm{CO}_{2}$ for $16 \mathrm{~h}$. The tubes/networks were stained with $4 \mu \mathrm{g} / \mathrm{ml}$ calcein (Invitrogen) for $30 \mathrm{~min}$ at $37^{\circ} \mathrm{C}$ and imaged using Metamorph image analysis software (Molecular Devices, Sunnyvale, CA).

DLD-1 xenograft tumor growth. DLD-1 human colon carcinoma cells and human MSC were cultured as described above, collected by brief exposure to trypsin, and washed twice with serum-free media. The cells were suspended in a 1:1 mixture of RPMI medium and Matrigel (Invitrogen) $(200 \mu 1)$ and injected subcutaneously into the rear flank region of $\mathrm{CB} 17 / \mathrm{ICrCrl}-\mathrm{scid}-\mathrm{bgBR}$ male mice, 6-7 weeks of age. Ten mice per group were inoculated with $5 \times 10^{6}$ DLD-1 cells or $1 \times 10^{5}$ MSC and $5 \times 10^{6}$ DLD- 1 cells. Tumor volumes were measured twice weekly. Tumor volume was calculated using the formula: volume $=$ width $^{2} \mathrm{x}$ length $\mathrm{x} 0.52$. Several tumors per group were collected at day 14 for immunohistochemistry and the remaining mice were continued on study until day 29. Experiments were carried out in compliance with the institution's IACUC committee in an AAALAC accredited facility.
Immunohistochemistry (IHC). For immunofluorescent images, frozen samples were fixed for $10 \mathrm{~min}$ in paraformaldehyde and blocked with $10 \%$ goat serum for $15 \mathrm{~min}$. Anti-human endosialin (10 $\mu \mathrm{g} / \mathrm{ml}$; Genzyme) was added to the slides with anti- $\alpha$ SMA or anti-PCNA at a 1:200 dilution (Dako) and allowed to incubate for $60 \mathrm{~min}$. The antibody to $\alpha \mathrm{SMA}$ reacts with both the human and murine proteins. Slides were washed for 5 min wash in TBS and secondary antibodies were added: anti-human-Cy3 (1:200), anti-mouse-Cy2 (1:100), (Jackson ImmunoResearch Laboratories), and incubated for $20 \mathrm{~min}$. Slides were washed for $5 \mathrm{~min}$ in TBS and mounted with DABCO antifade mounting medium (Sigma) countaining DAPI nuclear counterstain. Images were captured on an Olympus IX-71 inverted fluorescent microscope with a Hammamatsu CCD camera as red/green/blue images then overlaid with Metamorph image analysis software.

For brightfield images, FFPE tissues were deparaffinized through xylene and hydrated to distilled water with graded ethanols. Antigen retieval was achieved with acid citrate ( $\mathrm{pH}$ 6.0) for $15 \mathrm{~min}$ in a pressure cooker. Samples were blocked in $10 \%$ goat serum and slides were incubated for $60 \mathrm{~min}$ at RT with anti-human endosialin $(10 \mu \mathrm{g} / \mathrm{ml})$, washed $5^{\prime}$ in TBS, then detected with anti-human-biotin $(1.5 \mu \mathrm{g} / \mathrm{ml}$, Jackson Immunoresearch) for $20 \mathrm{~min}$. After a $5 \mathrm{~min}$ wash in TBS, the slides were incubated with $\mathrm{ABC}$ Elite (Vector Labs) for $20 \mathrm{~min}$, washed for $5 \mathrm{~min}$ in TBST (TBS/0.5\% Tween-20), then detected with DAB (Dako), counterstained with hematoxylin, cleared in xylene then mounted with permount.

\section{Results}

Tumor stroma includes fibroblasts, extracellular matrix, pericytes, endothelial cells, and infiltrating inflammatory cells that provide a microenvironment which supports tumor progression and metastasis (30). Since endosialin has been detected in the stromal fibroblasts of mouse embryos (23), we have investigated the expression of endosialin in fibroblasts of human tumors. Using a monoclonal antibody against endosialin, in addition to vascular staining in the specimens, the endosialin protein was found in the stromal regions of several types of carcinomas, breast, colon, and ovarian, by immunohistochemical methods (Fig. 1).

Carcinoma associated fibroblasts (CAF) were subsequently isolated from several fresh human breast tumors and propagated in culture in media with $2 \%$ FBS and several growth factors (IGF-1, bFGF, and EGF) that better supported cell growth than media with a higher serum content and no exogenous supplements. The breast CAF were initially quiescent in vitro for $\sim 5$ days followed by a rapid burst of proliferation. The cells presented an elongated and spindled morphology (Fig. 2A). The CAF were characterized at passage 2-3 by the production of fibroblast surface protein, fibronectin, SDF-1, and the absence of CXCR4, an endothelial cell marker (Fig. 2B). Flow cytometry confirmed robust expression of endosialin and also revealed that CAF present TEM 8/ANTXR1 and lower levels of TEM 3 (31). TEM 2, 4, and 5 were not detectable.

Since human MSC have been shown to differentiate into CAF-like cells and embryonic mesenchyme consist of 

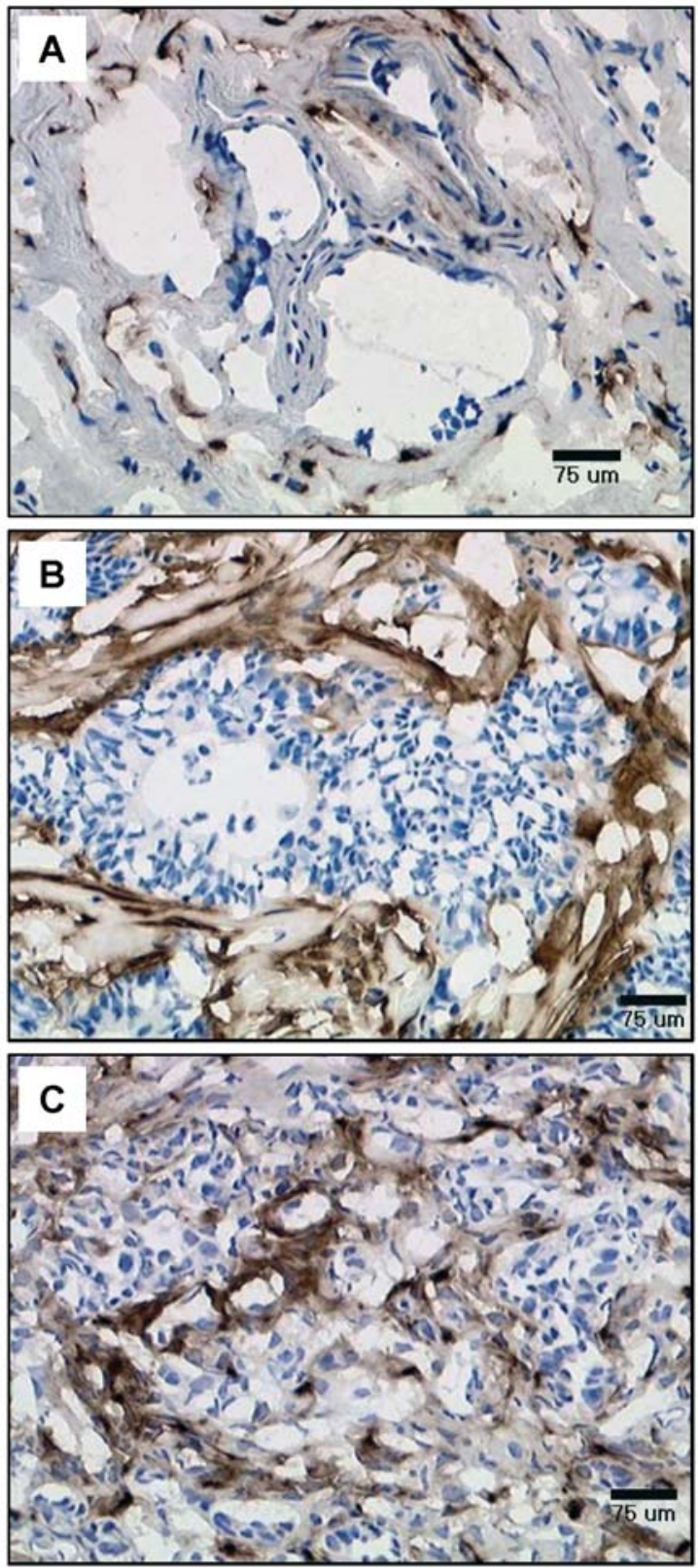

Figure 1. Endosialin/TEM 1 expression in breast cancer CAF. (A) Immunohistochemical staining for endosialin in frozen sections of human carcinomas at magnification $\mathrm{x} 20$. Anti-human endosialin binding was visualized with a tyramide amplification protocol using endosialin (DAB-brown) and hematoxylin/eosin staining to identify nuclei (blue). (A) Moderately differentiated infiltrating ductal breast carcinoma (B) invasive colon adenocarcinoma (C) poorly differentiated ovarian carcinoma. Scale bars, $75 \mu \mathrm{m}$.

fibroblasts, our investigation into endosialin advanced into human bone-marrow derived MSC (25). MSC can differentiate into multiple cell lineages including adipocytes as determined by oil red $\mathrm{O}$ staining (Fig. 3A). RT-PCR methods were employed to determine the molecular expression of endosialin as well as other TEM mRNA by the pluripotent MSC (Fig. 3B). Endosialin was more highly expressed than TEM 3, 5, 7, 8/ANTXR1, and 9. MSC cell surface expression of several of the TEM proteins was evaluated by flow cytometry (Fig. 3C) (11). Similar to CAF from the human breast carcinomas, MSC expressed high levels of endosialin as well as TEM 8/ANTXR1, but not TEM 2. There was moderate expression of TEM 4 and TEM 5 in MSC that were absent in CAF compared to TEM 3 that was present only in CAF. TEM 7 also was not detectable in MSC.

Endothelial cells are routinely used in phenotypic angiogenesis assays such as cell-based tube formation, to screen potential drug candidates. When plated on growth factor reduced Matrigel, MSC are also capable of forming tubes or networks. This assay may be of value in evaluating targets and therapies directed toward MSC phenotypic behavior. Overnight MSC tube formation was prevented by exposure to anti-endosialin (Fig. 4A-D). However, this effect was only observed when the MSC were pre-incubated with the anti-endosialin for $30 \mathrm{~min}$ in suspension. When the antibody was added to the culture at the time the MSC were plated onto Matrigel the MSC formed networks and the attachment and migration processes were not inhibited. Recently extracellular matrix proteins such as fibronectin were shown to bind with endosialin (20). It may be that anti-endosialin interferes with the interaction between cell surface endosialin and the Matrigel matrix. Anti-endosialin inhibition of MSC tube formation was quantified through image analysis by determining the length of tubes. At the $5.6 \mu \mathrm{g} / \mathrm{ml}$ antibody concentration there was a $70 \%$ decrease in tube length $(\mathrm{p}<0.01)$ while $4.2 \mu \mathrm{g} / \mathrm{ml}$ of anti-endosialin produced a $50 \%$ reduction in tube length (Fig. 4E).

The co-injection of fibroblasts or human MSC with human breast cancer cells results in more rapid tumor growth and metastasis than the delivery of cancer cells alone $(24,25,30)$. Endosialin is prevalent in the stroma of human colon carcinomas (Fig. 1B). The potential role of these endosialin expressing cells was explored by comparing the growth of tumors developed from co-injection of endogenously endosialin-expressing human MSC and human DLD-1 colon cancer cells with tumors developed from the implantation of DLD-1 colon cancer cells alone. The subcutaneous tumors arising from the co-injection of the MSC/DLD-1 mixture grew faster than tumors generated from the DLD-1 cells alone $(\mathrm{p}<0.01)$ (Fig. 5A). The tumor growth rate with the addition of the MSC was higher throughout the duration of the study. The tumor volume on day 29 post-injection of MSC/DLD-1 cells was $~ 50 \%$ greater compared to control tumors [1857 $\pm 298 \mathrm{~mm}^{3}(\mathrm{n}=10)$ vs. $\left.1206 \pm 153 \mathrm{~mm}^{3}(\mathrm{n}=10)\right]$.

Since anti-endosialin is specific for human endosialin and does not cross-react with the murine homologue of endosialin, immunohistochemistry performed with anti-endosialin was able to detect the human MSC in DLD-1/ \pm MSC xenograft sections. There was no endosialin detected in the tumors without human MSC in the implants, thus the vascular and stromal cells in these tumors were murine (Fig. 5B). After two weeks of growth, the DLD-1 tumors implanted with human MSC showed clear expression of human endosialin (Fig. 5C). Endosialin-expressing MSC were frequently detected at sites distal from vasculature toward the outer edge of the xenograft tumor nodules, a location typically characterized by proliferation and rapid growth. Double immunofluorescent staining for human TEM 1 and proliferating cell nuclear antigen (PCNA) indicated that MSC were actively dividing in vivo in the tumor microenvironment (Fig. 5D). Human MSC in the xenograft tumors were negative 


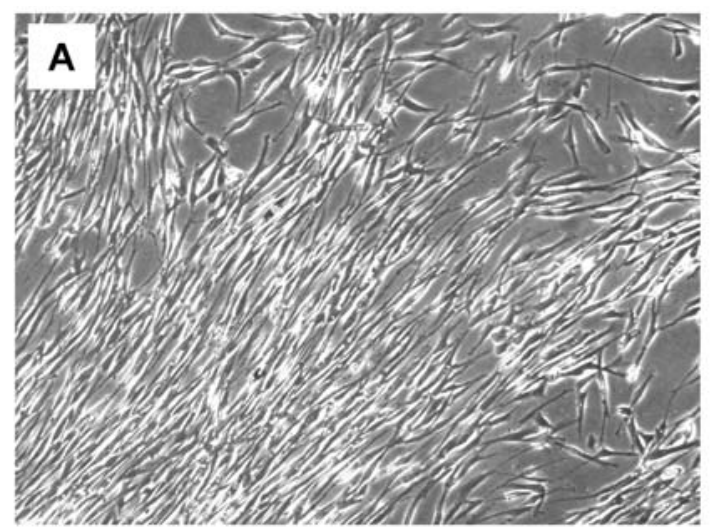

for human CD31 and NG2 by double immunofluorescent methods indicating that the MSC had not differentiated into endothelial cells or pericytes (data not shown). By contrast, human $\alpha \mathrm{SMA}$ expression co-localized with endosialin in MSC in the DLD-1 tumors (Fig. 5E). The presence of human MSC in larger numbers and distal from areas of angiogenesis indicates the contribution of these cells to the tumor stroma. This finding is consistent with the observation that MSC delivered systemically homed to developing HT29 colon carcinoma xenograft tumors and were incorporated into the stroma (32).

B
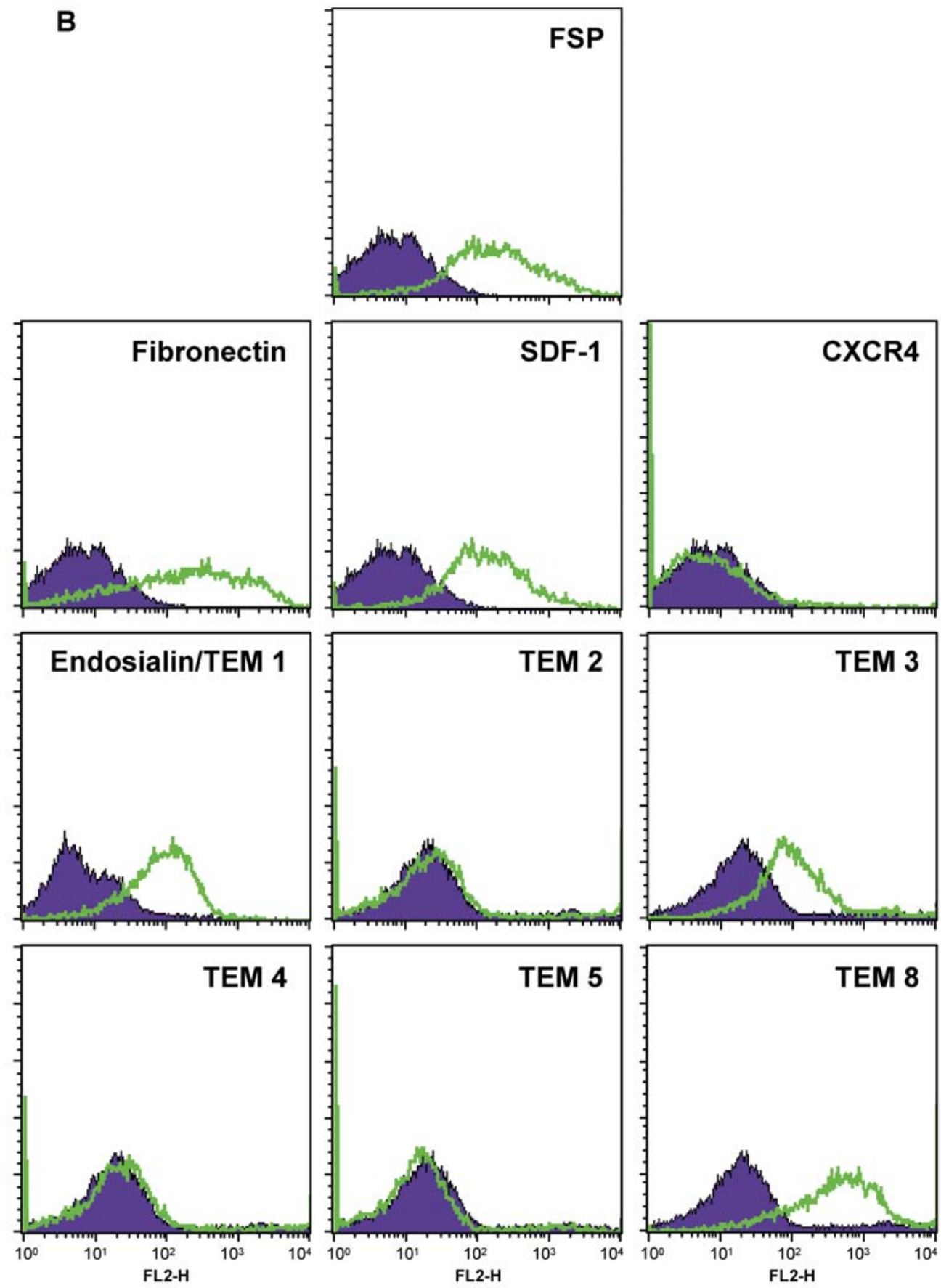

Figure 2. Endosialin and TEM expression in human breast cancer CAF. (A) CAF were isolated from human breast carcinomas and cultured in vitro. Bright field image of CAF at magnification $\mathrm{x} 4$. (B) CAF were characterized by flow cytometry and express fibroblast surface protein (FSP), fibronectin, and SDF-1. CAF did not express the endothelial cell marker CXCR4. CAF express endosialin/TEM 1 as well as TEM 3 and TEM 8. CAF did not express TEM 2, 4 or 5. Solid profiles represent isotype control primary antibody. 
A

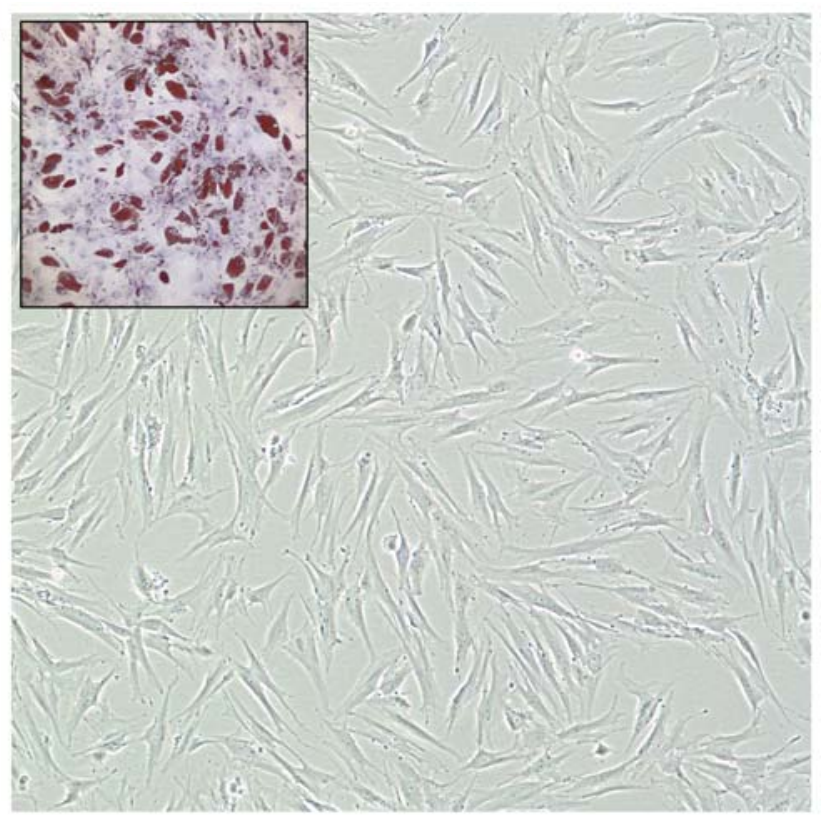

B

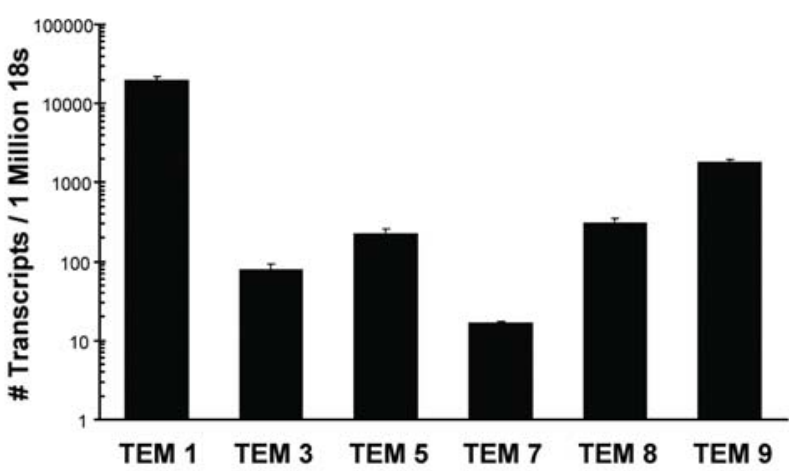

Figure 3. MSC express endosialin and TEM. (A) MSC were imaged at magnification $\times 10$. Inset, MSC are capable of differentiating into adipocytes. Oil red O staining is indicative of lipid-rich vacuoles. (B) RT-PCR was performed to evaluate the molecular expression of TEM in MSC. Endosialin was more highly expressed than TEM 4, 5, 8, and 9. There were neglible levels of TEM 3 and 7. (C) Endosialin and TEM proteins were determined by flow cytometry. Endosialin was expressed at greater levels than TEM 4, 5 , and 8 . There was no expression of TEM 2 or 3 . Solid profiles represent isotype control primary antibody.

\section{Discussion}

MSC and bone marrow-derived fibroblasts/myofibroblasts are implicated in the progression of malignant disease (33-35). The differentiation of human bone marrow-derived MSC into CAF has been demonstrated in vitro $(25,36)$. In addition to endosialin in vascular components, several human carcinomas (breast, colon, and ovarian) have robust endosialin expression in stromal cells. In culture, CAF isolated from human breast tumors and human MSC from bone marrow express high levels of endosialin and are either negative for or express low levels of TEM 2, 3, 4, 5 and 7. Our human endosialin-specific monoclonal antibody allowed identification of human MSC in DLD-1 colon carcinoma xenograft tumors generated from the co-injection of MSC and DLD-1 colon carcinoma cells. This experiment demonstrated that endosialin expression is maintained by MSC in an in vivo tumor microenvironment while co-expressing a marker of fibroblasts, $\alpha$ SMA, and

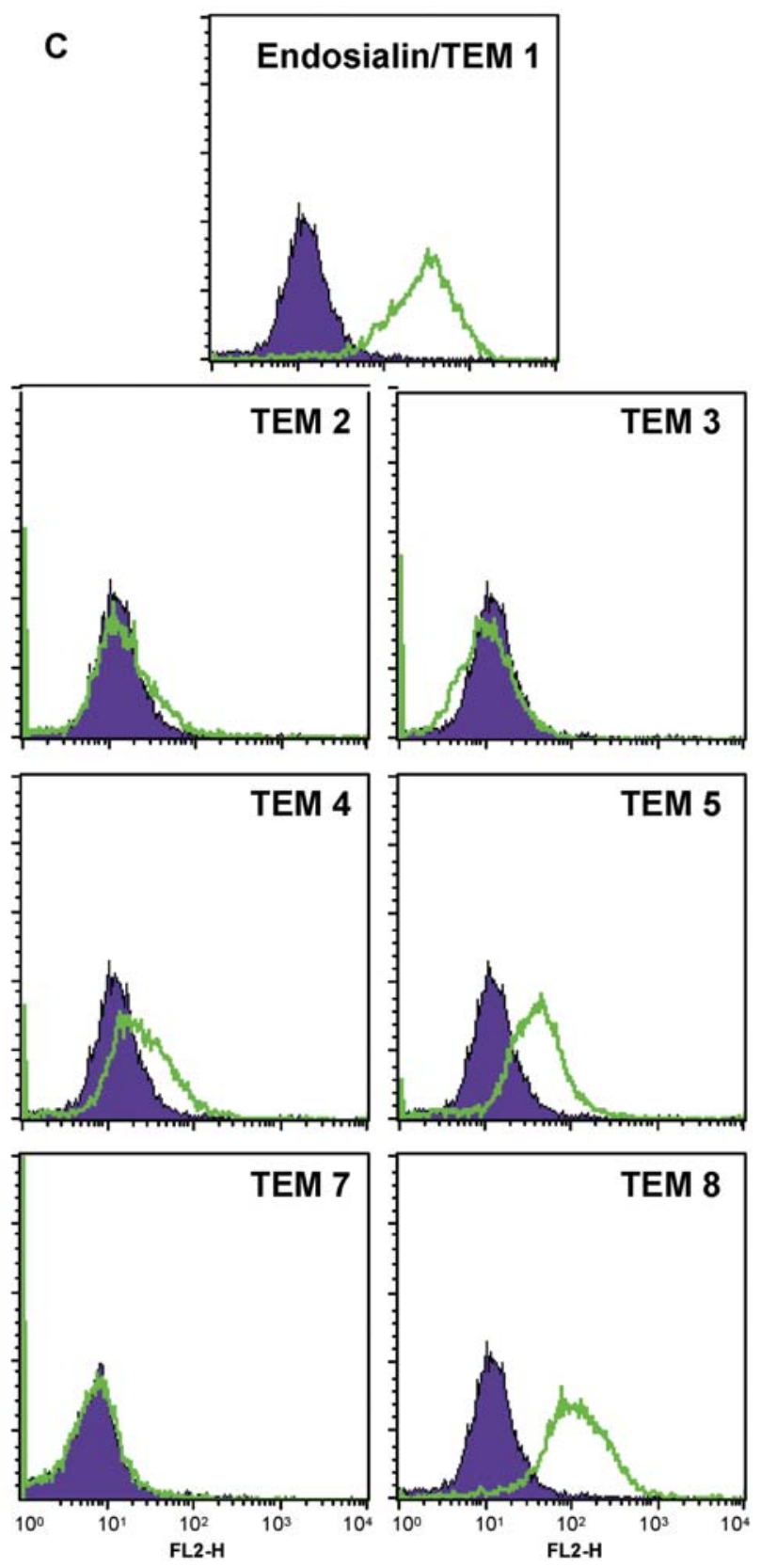

that the human MSC remained viable and proliferated as a component of the malignant tumor in the mouse.

This report is the first to describe the protein expression of TEM 8/ANTXR1 by breast CAF ex vivo as well as by MSC. TEM 8 has previously been observed in breast cancer cell lines, endothelial cells and a human embryonic fibroblast cell line (37). TEM 8 has been correlated with more aggressive breast and colon cancers and is often expressed by melanoma $(13,38,39)$. The screening for other TEM in breast CAF and MSC revealed co-expression of TEM 8 with endosialin but not TEM 2, 3, 4, or 5 in both primary cell types. The coexpression of endosialin and TEM 8 in MSC further supports the hypothesis that CAF are derived from MSC and can promote malignant disease. In addition to other characteristics, the differential expression of TEM 3, 4, and 5 between CAF and MSC distinguish the two cell types.

As the role of endosialin in tumor progression continues to be elucidated, the novel anti-endosialin and the MSC tube 

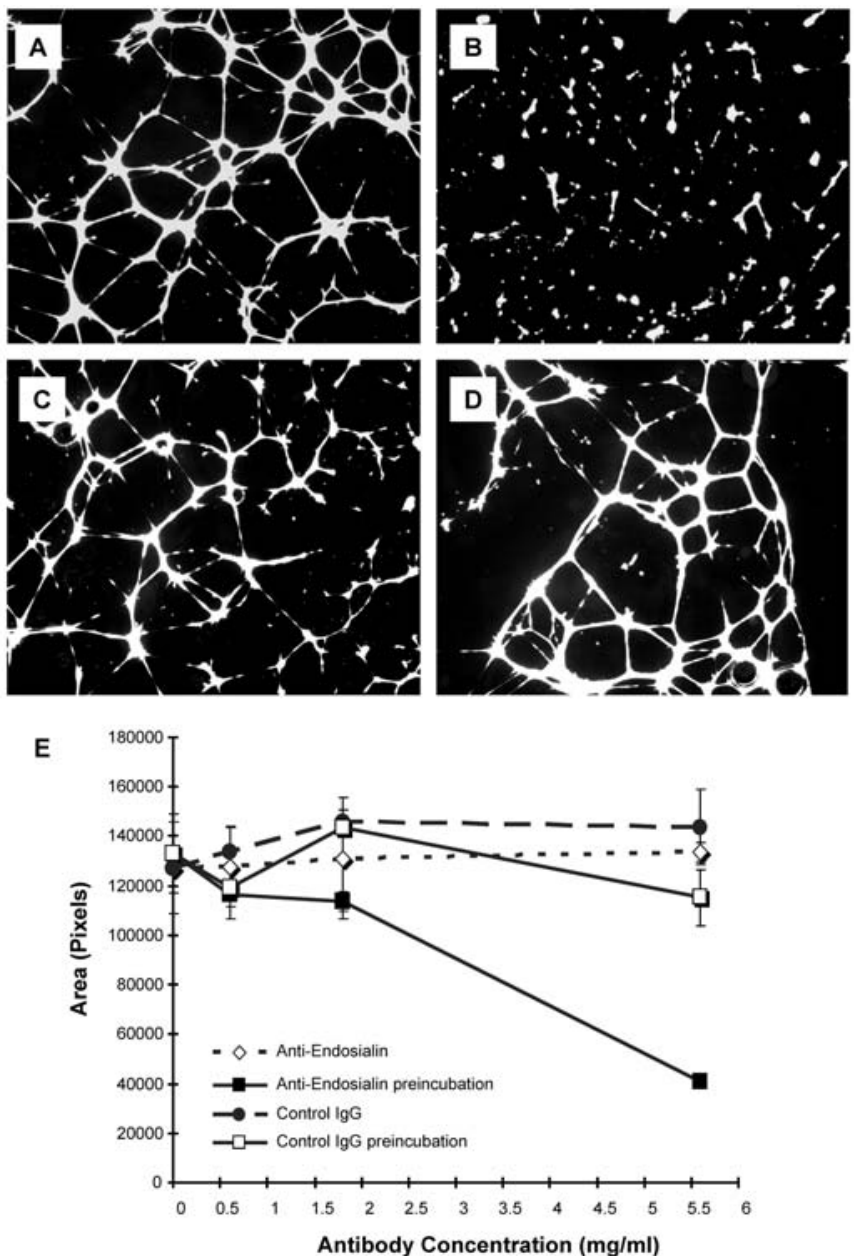

Figure 4. Anti-endosialin inhibits MSC tube formation. (A) MSC form networks on Matrigel within $24 \mathrm{~h}$. (B) Anti-endosialin at $5.6 \mu \mathrm{g} / \mathrm{ml}$ prevented the formation of MSC tubes when the antibody was preincubated with MSC prior to seeding in the assay. (C) Control antibody at $5.6 \mu \mathrm{g} / \mathrm{ml}$ had little effect on MSC activity. (D) The inhibitory effect of anti-endosialin is not effective when the antibody is not pre-incubated with the MSC. (E) A concentration response curve demonstrates the significant effect of anti-endosialin on MSC tube formation (Student's t-test, $\mathrm{p}<0.01 ; \mathrm{n}=3$ ). Values represent mean $\pm \mathrm{SD}$.

formation assay described expand upon findings regarding the role of endosialin expression by cell types that can form tubes/networks as a function. Extracellular matrix proteins such as collagen types I, IV and fibronectin interact with endosialin to mediate cell adhesion and migration (20). In the tube formation assay, MSC were incapable of forming networks following exposure to anti-endosialin. Exposure to anti-endosialin may inhibit the ability of MSC to firmly attach and extend across the extracellular matrix indicating that endosialin is involved in the earlier stages of the tube formation process by facilitating interaction of the cell with the microenvironment. The tubes/networks that MSC can establish may provide structural support in vivo as stroma or could potentially serve as a framework for vascular development during periods of active angiogenesis. Anti-endosialin was also effective at preventing tube/network formation by pericytes and endothelial precursor cells indicating that targeting endosialin can influence multiple cell types which contribute to tumor growth associated with vasculature and stroma $(40,41)$.
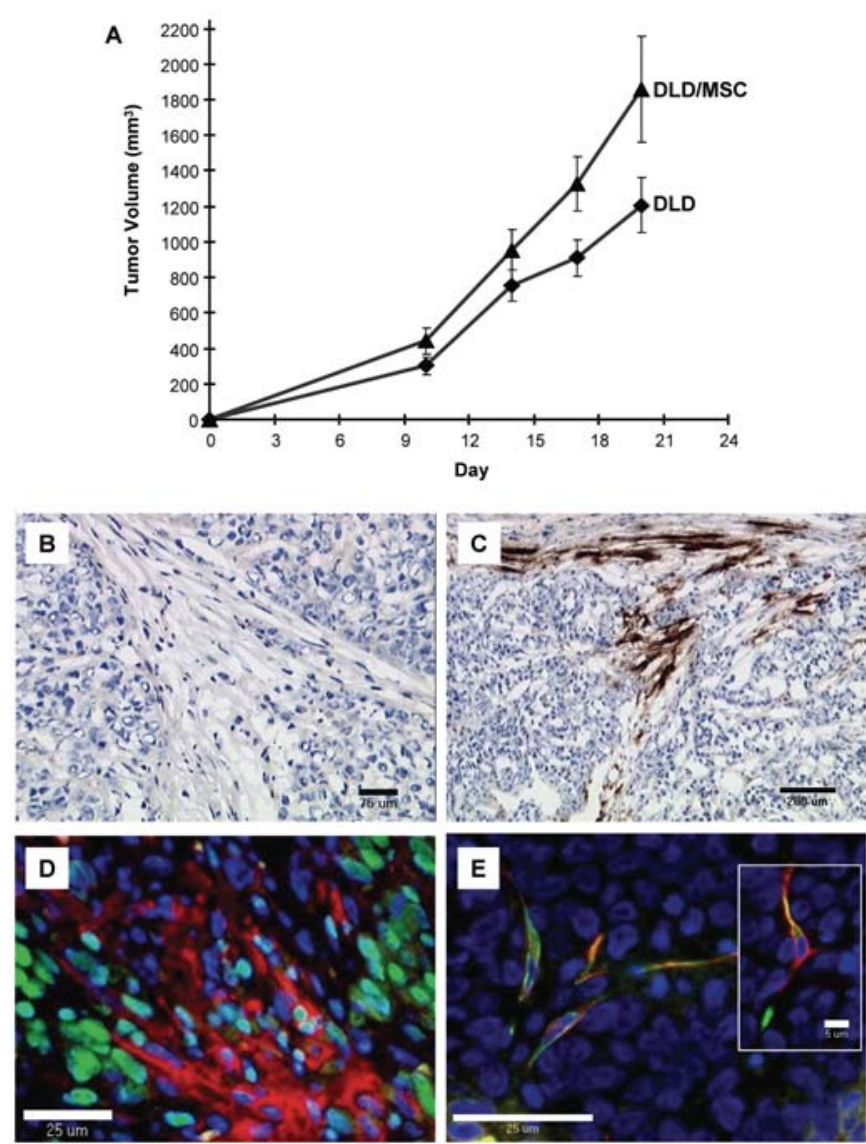

Figure 5. MSC participate in the stromal compartment of xenograft tumors. (A) The tumor growth rate for the MSC/DLD-1 tumors was 1.9-fold faster than tumors arising from the injection of DLD-1 cells only (two-way ANOVA analysis, $\mathrm{p}=0.01 ; \mathrm{n}=10$ ). (B) Immunohistochemical staining of tumors from implant of DLD-1 cells alone with anti-endosialin shown no staining indicating that the monoclonal antibody does not cross-react with murine endosialin. These tumors have murine-derived stroma and vasculature. Scale bar, $75 \mu \mathrm{m}$. (C) Immunohistochemical staining of tumors from implant of human MSC $\left(10^{5}\right)$ along with DLD-1 colon carcinoma cells $\left(5 \times 10^{6}\right)$ to form subcutaneous tumors with anti-endosialin. Human endosialin was readily apparent indicating that human MSC contribute to the stroma of the tumors. Scale bar, $200 \mu \mathrm{m}$. (D) Double immunofluorescent methods for PCNA (green) and human endosialin (red) in MSC indicated that MSC are proliferating in the DLD-1 xenograft tumors (light blue nuclei). As expected, PCNA was also detected in the cancer cells (green). Nuclei of cells that are not dividing are darker blue in color by by the nuclear stain DAPI. Scale bar, $25 \mu \mathrm{m}$. (E) An antibody that binds to both human and murine aSMA (green) showed coincident staining (yellow) of cells expressing human endosialin (red) in human MSC of MSC/DLD-1 tumors. Nuclei are stained with DAPI (blue). The human MSC present an elongated, spindloid, and fibroblast-like morphology. Scale bars, 25 and $5 \mu \mathrm{m}$ (inset).

Focused regions of MSC were often present near the periphery of the DLD-1 colon carcinoma xenografts. In xenograft tumors the periphery is frequently a site of active proliferation compared to the tumor center that can be necrotic. The outer edge of the tumor is sometimes referred to as the 'viable rim' and can initiate re-growth when cytotoxic therapy has killed the reminder of the tumor nodule. Anti-tumor vascular disrupting agents often fail to affect this portion of the tumor when administered as single agent thereby necessitating combination regimens with chemotherapy or radiotherapy to achieve tumor control (42). Endogenous MSC derived from bone marrow or residing in nearby host 
tissues can be mobilized migrate to malignant tissue and contribute to the extensive stroma associated with resistance to anti-cancer treatments.

Breast CAF and MSC promote the progression of disease in preclinical tumor models $(5,10,24)$. This may also be the case in human cancers. Mac-2 BP/90K, a secreted glycoprotein that binds galectins, $\beta 1$-integrins, collagens and fibronectin and has a role in cell-cell and cell-extracellular matrix adhesion, is recognized as a binding partner of endosialin (19). High intratumoral levels of Mac-2BP/90K were associated with worse outcomes for patients with stage I non-small cell lung carcinoma (43).

Preclinically, a vaccine targeting CAF expressing fibroblast activation protein (FAP) resulted in reduction in CT26 colon carcinoma tumor growth by increasing in drug uptake by the tumor and translated into increased survival (44). Since tumor vascular cells also express endosialin, an endosialindirected therapy would be a multi-cellular treatment agent targeting both vasculature and stroma involved in the malignant disease process. Although knockout mice lacking endosialin were able to sustain the growth of orthotopic abdominal tumors, take-rate, size, invasiveness, and metastatic potential of the tumors was reduced supporting the notion that disruption of endosialin-expressing cells may provide clinical benefit (45). Although endosialin was described to be a tumor endothelial marker implying selective endothelial cell expression for endosialin, expression of endosialin has been documented in other cell types (11). Endosialin has been detected in fibroblasts, perivascular in the tumor microenvironment and mesenchymal malignant cells $(14,16,21,41,46)$.

Multiple antibodies to endosialin have been developed. The first, a murine antibody designated FB5, was used to identify endosialin in tumor tissue (17). Another antiendosialin was used in laser capture microdissection to isolate fibroblasts for transcriptional profiling of human cancer biopsies (47). Preclinical studies demonstrated that an anti-endosialin coupled to lipids loaded with a cytotoxic drug was an effective therapeutic against human IMR-32 neuroblastoma cells endogenously expressing endosialin (48). An anti-endosialin antibody may have value as a prognostic tool to assess stromal and vascular involvement in tumors and, in addition, targeting CAF and MSC with anti-endosialin or a toxin-conjugated antibody may be of therapeutic benefit. Since endosialin is prevalent in human tumors in stroma and vasculature, endosialin-targeted therapeutics may be useful in combination with therapies directed toward the malignant cell.

\section{References}

1. Teicher BA: Malignant cells, directors of the malignant process: role of transforming growth factor beta. Cancer Met Rev 20: 133-143, 2001.

2. Tredan O, Galmarini CM, Patel K and Tannock IF: Drug resistance and the solid tumor microenvironment. J Natl Cancer Inst 99: 1441-1454, 2007.

3. Hawsawi NM, Ghebeh H, Hendrayani S-F, et al: Breast carcinoma-associated fibroblasts and their counterparts display neoplastic-specific changes. Cancer Res 68: 2717-2725, 2008.

4. Nakagawa H, Liyanarachchi S, Davuluri RV, Auer H, Martin EW Jr, De la Chapelle A and Frankel WL: Role of cancerassociated stromal fibroblasts in metastatic colon cancer to the liver and their expansion profiles. Oncogene 23: 7366-7377, 2004.
5. Olumi AF, Grossfeld GD, Hayward SW, Carroll PR, Tlsty TD and Cunha GR: Carcinoma-associated fibroblasts direct tumor progression of initiated human prostatic epithelium. Cancer Res 59: 5002-5011, 1999

6. Kalluri R and Zeisberg M: Fibroblasts in cancer. Nat Rev Cancer 6: 392-401, 2006

7. Studeny M, Marini FC, Champlin RE, Zompetta C, Fidler IJ and Andreeff M: Bone marrow-derived mesenchymal stem cells as vehicles for interferon-b delivery into tumors. Cancer Res 62: 3603-3608, 2002

8. Spaeth E, Klopp A, Dembinski J, Andreeff M and Marini F: Inflammation and tumor microenvironments: defining the migratory itinerary of mesenchymal stem cells. Gene Ther 15: 730-738, 2008.

9. Lebret SC, Newgreen DF, Thompson EW and Ackland ML: Induction of epithelial to mesenchymal transition in PMC24-LA human breast carcinoma cells by carcinoma-associated fibroblast secreted factors. Breast Cancer Res 9: R19, 2007.

10. Orimo A, Gupta PB, Sgroi DC, et al: Stromal fibroblasts present in invasive human breast carcinomas promote tumor growth and angiogenesis through elevated SDF-1/CXCL12 secretion. Cell 121: 335-348, 2005 .

11. St. Croix B, Rago C, Velculescu V, et al: Genes expressed in human tumor endothelium. Science 289: 1197-1202, 2000.

12. Brady J, Neal J, Sadakar N and Gasque P: Human endosialin (tumor endothelial marker 1) is abundantly expressed in highly malignant and invasive brain tumors. J Neuropath Exp Neurol 63: 1274-1283, 2004

13. Davies G, Cunnick GH, Mansel RE, Mason MD and Jiang WG: Levels of expression of endothelial markers specific to tumourassociated endothelial cells and their correlation with prognosis in patients with breast cancer. Clin Exp Metastasis 21: 31-37, 2004.

14. Dolznig H, Schweifer N, Puri C, Kraut N, Rettig W, Kerjaschki D and Garin-Chesa P: Characterization of cancer stroma markers: in silico analysis of an mRNA expression database for fibroblast activation protein and endosialin. Cancer Immun 5: 1-9, 2005.

15. Madden SL, Cook BP, Nacht M, et al: Vascular gene expression in non-neoplastic and malignant brain. Am J Pathol 165: 601-608, 2004.

16. Rouleau C, Curiel M, Weber W, et al: Comprehensive assessment of endosialin protein expression in human cancer: therapeutic implications for synovial sarcoma, fibrosarcoma, malignant fibrous histiocytoma, liposarcoma and osteosarcoma. Clin Cancer Res 14: 7223-7236, 2008.

17. Rettig W, Garin-Chesa P, Healey JH, Su SL, Jaffe EA and Old LJ: Identification of endosialin, a cell surface glycoprotein of vascular endothelial cells in human cancer. Proc Natl Acad Sci USA 89: 10832-10836, 1992.

18. Christian S, Ahorn H, Koehler A, Eisenhaber F, Rodi HP, Garin-Chesa P, Park JE, Rettig WJ and Lenter MC: Molecular cloning and characterization of endosialin, a C-type lectin-like cell surface receptor of tumor endothelium. J Biol Chem 276: 7408-7414, 2001.

19. Becker R, Lenter MC, Vollkommer T, Boos AM, Pfaff D, Augustin HG and Christian S: Tumor stroma marker endosialin (Tem1) is a binding partner of metastasis-related protein Mac-2 BP/90K. FASEB J 22: 1-9, 2008.

20. Tomkowicz B, Rybinski K, Foley B, et al: Interaction of endosialin/TEM 1 with extracellular matrix proteins mediates cell adhesion and migration. Proc Natl Acad Sci USA 104: 17965-17970, 2007.

21. Huber MA, Kraut N, Schweifer N, et al: Expression of stromal cell markers in distinct compartments of human skin cancers. J Cutan Pathol 33: 145-155, 2006.

22. Lax S, Hou TZ, Jenkinson E, et al: CD248/endosialin is dynamically expressed on a subset of stromal cells during lymphoid tissue development, splenic remodeling and repair. FEBS Lett 581: 3550-3556, 2007.

23. MacFadyen J, Savage K, Wienke D and Isacke CM, et al: Endosialin is expressed on stromal fibroblasts and CNS pericytes in mouse embryos and is downregulated during development. Gene Express Patterns 7: 363-369, 2007.

24. Karnoub, AE, Dash AB, Vo AP, et al: Mesenchymal stem cells within tumour stroma promote breast cancer metastasis. Nature 449: 557-565, 2007.

25. Mishra PJ, Mishra PJ, Humeniuk R, et al: Carcinoma-associated fibroblast-like differentiation of human mesenchymal stem cells. Cancer Res 68: 4331-4339, 2008. 
26. Pittenger MF, Mackay AM, Beck SC, et al: Multilineage potential of adult human mesenchymal stem cells. Science 284 : 143-147, 1999

27. Dexter DL, Barbosa JA and Calabresi P, et al: N, N-dimethylformamide-induced alteration of cell culture characteristics and loss of tumorigenicity in cultured human colon carcinoma cells. Cancer Res 39: 1020-1025, 1979

28. Ishida I, Tomizuka K, Yoshida H, et al: Production of human monoclonal and polyclonal antibodies in TransChromo animals. Cloning Stem Cells 4: 91-102, 2002.

29. Tomizuka K, Shinohara T, Yoshida H, et al: Double transchromosomic mice: maintenance of two individual human chromosome fragments containing Ig heavy and $\mathrm{k}$ loci and expression of fully human antibodies. Proc Natl Acad Sci USA 97: 722-727, 2000.

30. Noel A and Foidart J-M: The role of stroma in breast carcinoma growth in vivo. J Mammary Gland Biol Neoplasia 3: 215-225, 1998.

31. Nanda A and St Croix B: Tumor endothelial markers: new targets for cancer therapy. Curr Opin Oncol 16: 44-49, 2004.

32. Hung SC, Deng WP, Yang WK, et al: Mesenchymal stem cell targeting of microscopic tumors and tumor stroma development monitored by noninvasive in vivo positron emission tomography imaging. Clin Cancer Res 11: 7749-7756, 2005.

33. Direkze NC, Hodivala-Dilke K, Jeffery R, et al: Bone marrow contribution to tumor-associated myofibroblasts and fibroblasts. Cancer Res 64: 8492-8495, 2004.

34. Klopp AH, Spaeth EL, Dembinski JL, et al: Tumor irradiation increases the recruitment of circulating mesenchymal stem cells into the tumor microenvironment. Cancer Res 67: 11687-11695, 2007.

35. Ishii G, Sangai T, Oda T, et al: Bone-marrow-derived myofibroblasts contribute to the cancer-induced stromal reaction. Biochem Biophys Res Commun 309: 232-240, 2003.

36. Emura M, Ochiai A, Horino M, Arndt W, Kamino K and Hirohashi S: Development of myofibroblasts from human bone marrow mesenchymal stem cells cocultured with human colon carcinoma cells and TGF beta 1. In Vitro Cell Dev Biol Anim 36: 77-80, 2000.

37. Davies G, Rmali KA, Watkins G, Mansel RE, Mason MD and Jiang WG: Elevated levels of tumour endothelial marker-8 in human breast cancer and its clinical significance. Int J Oncol 29: 1311-1317, 2006.
38. Rmali K, Puntis M and Jiang W: Prognostic values of tumor endothelial markers in patients with colorectal cancer. World J Gastroenterol 11: 1283-1286, 2005.

39. Rouleau C, Menon K, Boutin P, et al: The systemic administration of lethal toxin achieves a growth delay of human melanoma and neuroblastoma xenografts: assessment of receptor contribution. Int J Oncol 32: 739-748, 2008.

40. Bagley R, Rouleau C, St. Martin T, et al: Human endothelial precursor cells express tumor endothelial marker 1/endosialin/ CD248. Mol Cancer Ther 7: 2536-2546, 2008.

41. Bagley R, Honma N, Weber W, et al: Endosialin/TEM 1/CD248 is a pericyte marker of embryonic and tumor neovascularization. Microvasc Res 76: 180-188, 2008.

42. Gaya AM and Rustin GJS: Vascular disrupting agents: a new class of drug in cancer therapy. Clin Oncol 17: 277-290, 2005.

43. Marchetti A, Tinari N, Buttitta F, et al: Expression of $90 \mathrm{~K}$ (Mac-2 BP) correlates with distant metastasis and predicts survival in stage I non-small cell lung cancer patients. Cancer Res 62: 2535-2539, 2002.

44. Loeffler M, Kruger JA, Niethammer AG and Reisfeld RA: Targeting tumor-associated fibroblasts improves cancer chemotherapy by increasing intratumoral drug uptake. J Clin Invest 116: 1955-1962, 2006.

45. Nanda A, Karim B, Peng Z, et al: Tumor endothelial marker 1 (Tem 1) functions in the growth and progression of abdominal tumors. Proc Natl Acad Sci USA 103: 3351-3356, 2006.

46. Virgintino D, Girolamo F, Errede M, et al: An intimate interplay between precocious, migrating pericytes and endothelial cells governs human fetal brain angiogenesis. Angiogenesis 10: 35-45, 2007.

47. Rupp C, Dolznig H, Puri C, et al: Laser capture microdissection of epithelial cancers guided by antibodies against fibroblast activation protein and endosialin. Diagn Mol Pathol 15: 35-42, 2006.

48. Marty C, Langer-Machova Z, Sigrist S, Schott H, Schwendener R and Ballmer-Hofer $\mathrm{K}$ : Isolation and characterization of a $\mathrm{scFv}$ antibody specific for tumor endothelial marker 1 (TEM 1), a new reagent for targeted tumor therapy. Cancer Lett 235: 298-308, 2006. 